\title{
Fuzzy Logic Control of Saturated Induction Machine
}

\author{
Mona N.Eskander \\ Electronics Research Institute \\ Department of Power Electronics \\ Dokki, Cairo, Egypt
}

\begin{abstract}
In this paper, two methods for controlling saturated slip power recovery drives (SSPRD) are studied and compared. To account for saturation, a polynomial approximation is used for the proper account of the nonlinear magnetization reactance. Fuzzy logic (FL) is then proposed for intelligent control of the saturated slip power recovery drive. The characteristics of the FL controlled SSPRD during start up is presented. The FL controlled system responses to step changes in the reference speed, load torque, and parameters variation are presented. A comparison between the responses of a PI controlled SSPRD and the FL controlled SSPRD to variations in reference speed, in load torque, and in rotor resistance, is obtained. Results proved that the FL controlled SSPRD attains faster responses, accurate speed tracking, higher load disturbance rejection, and lower sensitivity to parameters variation, than the PI controlled SSPRD.
\end{abstract}

\section{LIST OF SYMBOLS}

$\mathrm{R}_{s}$ and $\mathrm{R}_{r}$ : stator and rotor phase resistances (ohm)

$\mathrm{L}_{s}$ and $\mathrm{L}_{r}$ :stator and rotor self-inductances (henry)

$\mathrm{L}_{\mathrm{m}}$ :magnetizing inductance (henry)

$\mathrm{L}_{\mathrm{sl}}, \mathrm{L}_{\mathrm{rl}}$ : the stator and rotor leakage inductances respectively (henry)

$\mathrm{N}_{p}$ : number of pole pairs

$\mathrm{J}:$ the moment of inertia $\left(\mathrm{Kg} \cdot \mathrm{m}^{2}\right)$

$\mathrm{K}:$ the damping constant (Nm./rad./sec.)

$\mathrm{V}_{s}, \mathrm{~V}_{r}$ : the stator and rotor phase voltages respectively (volt)

$\mathrm{i}_{s}, \mathrm{i}_{r}:$ the stator and rotor phase currents respectively (amp)

Manuscript received from Dr. Mona .N. Eskander 


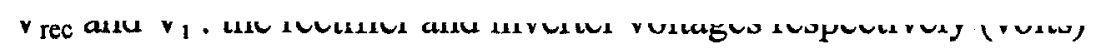

$\mathrm{i}_{\mathrm{dc}}$ is the dc link current (amp.)

$\mathrm{r}_{\mathrm{f}}: \mathrm{dc}$ link resistance $(\mathrm{ohm})$

$\mathrm{x}_{\mathrm{f}}$ : the dc link reactance $(\mathrm{ohm})$

$\Psi_{m}$ : the magnetizing flux linkages (web.)

$\underline{\mathrm{i}}_{m}$ : the magnetizing current(amp.)

$I_{m}$ : the absolute value of magnetizing current (amp.)

$\mathrm{d}$, q suffixes stand for direct and quadrature axis components

$\mathrm{i}_{\mathrm{md}}, \mathrm{i}_{\mathrm{mq}}$ : the $\mathrm{d}$ and $\mathrm{q}$ components of the magnetizing current(amp)

$\omega_{r} \quad$ : the rotor speed(rps)

$\mathrm{p}=\mathrm{d} / \mathrm{dt}$

$\mathrm{T}_{L}$ : load torque (N.m)

$\mathrm{T}_{\mathrm{e}}$ : electric torque(N.m.)

$\alpha:$ the inverter firing angle

\section{INTRODUCTION}

In many industries there is an essential demand for a precise and reliable variable speed drive capable of giving high dynamic performance for high power industrial applications. The slip-power-recovery drives (SPRD) are gaining a position of importance among the variable speed drives because of their higher efficiency, low initial cost, and simple control circuitry [1]. In such drives the rotor voltages of a 3phase wound-rotor induction motor are rectified and the resultant dc current is inverted via a 3-phase line commutated inverter and fed back to the supply. The speed of the drive is controlled by varying the firing angle of the inverter.To obtain high dynamic performance of SPRD, it is necessary to keep the magnetising current at a high level. At such level, the induction machine is saturated, and precise modeling of saturation is essential for accurate control purposes [2].

To achieve accurate speed control for saturated slip power recovery drive (SSPRD), the controller has to be of low sensitivity to parameter variations, and has to handle the non-linear drive characteristics. Fuzzy logic (FL) has emerged as a profitable tool for controlling non-linear systems . In particular, fuzzy logic approaches have recently been proposed to develop robust non-linear control systems for induction motor drives [3-8]. Such controllers are insensitive to parameter variations because their design is based only on system behaviour and the desired system performance. These characteristics renders FL as an ideal tool for speed control of SSPRD. To the author's knowledge, previous publications on application of $\mathrm{FL}$ controllers to induction machines were confined to machines with linear magnetics ,i.e. saturation effects were not considered [3-8].

In this paper two methods for controlling a saturated slip power recovery drive (SSPRD) are studied and compared; namely, the FL and the PI. To account for saturation, a polynomial approximation for the proper consideration of the nonlinear magnetizing reactance is derived from the induction machine no-load test. Introducing the saturation effect in the slip power recovery drive (SSPRD) equations, FL approach is utilized for speed control of the saturated drive. The FL controlled SSPRD responses to variation in the reference speed, in the load torque, and in the 
rotor resistance are deduced. The performance of the PI controlled SSPRD at variations of speed, torque, and rotor resistance are also presented. Comparison between the performances of the FL and the PI controlled SSPRD under these variations is then presented. Results proved that the FL controlled SSPRD attains faster responses, accurate speed tracking, higher load disturbance rejection, and lower sensitivity to parameter variations, than the PI controlled SSPRD.

\section{SYSTEM DESCRIPTION AND MODELING}

\subsection{Saturation Effect}

The slip power recovery drive consisting of a 3-phase slip ring induction motor, a diode bridge, a dc link, and a line commutated inverter is shown in Fig.(1). The prediction of saturated slip power recovery drive (SSPRD) performance requires proper account of the effect of saturation. To account for main flux saturation, the value of the nonlinear magnetizing reactance $\mathrm{X}_{\mathrm{m}}$ has to be determined. The magnetization characteristics are deduced by

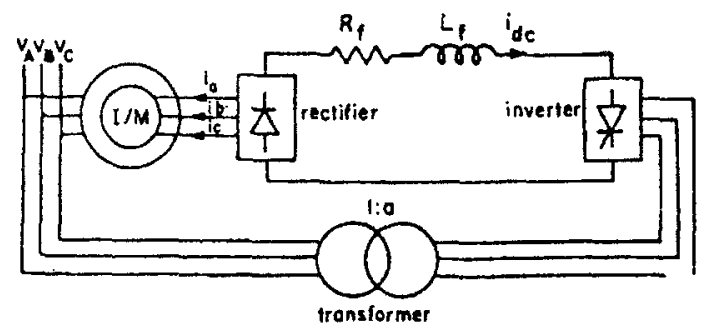

Fig(1)Schematic diagram of slip energy recovery system

applying the no-load test at synchronous speed. In this test, the machine is connected to a variable voltage at rated frequency, and the magnetizing current is measured as the no-load stator current. The values of the air gap emf $(E)$ and the magnetizing reactance $\left(\mathrm{X}_{\mathrm{m}}\right)$ are calculated for every set of corresponding values of the no-load test voltage $(V)$ and no-load test current $\left(\mathrm{I}_{\mathrm{m}}\right)$, Thus for the $\mathrm{k}^{\text {th }}$ set of values, $\mathrm{E}$ and $\mathrm{X}_{\mathrm{m}}$ are calculated as:

$E(k)=V(k)-\left(R_{s}+j X_{s}\right) * I_{m}(k)$

$X_{m}(k)=E(k) / I_{m}(k)$

A polynomial fitting routine is used. Given the values of the vector $I_{m}$, the routine finds an $n^{\text {th }}$ order polynomial $P$ such that $P\left(I_{m}\right)$ fits the values of vector $E$ in a least square sense. A good correlation is found for the third order polynomial fitting given by:

$E(k)=2.9289 \mathrm{I}_{\mathrm{m}}^{3}(\mathrm{k})-34.0315 \mathrm{I}_{\mathrm{m}}^{2}(\mathrm{k})+139.455 \mathrm{I}_{\mathrm{m}}(\mathrm{k})+0.5239$

The same procedure is used to fit the values of $I_{m}(k)$ with the values of $X_{m}$. A good correlation is found for the fifth order polynomial fitting given by:

$$
\mathrm{X}_{\mathrm{m}}(\mathrm{k})=-0.347 \mathrm{I}_{\mathrm{m}}^{5}(\mathrm{k})+3.9145 \mathrm{I}_{\mathrm{m}}^{4}(\mathrm{k})-16.6853 \mathrm{I}_{\mathrm{m}}^{3}(\mathrm{k})+21.8846 \mathrm{I}_{\mathrm{m}}^{3}(\mathrm{k})-
$$

$$
34.3611 \mathrm{I}_{\mathrm{m}}(\mathrm{k})+131.9594
$$

Plots of both measured characteristics $\left(E-I_{m}, X_{m}-I_{m}\right)$ and interpolated values are given in Figs.(2) and (3). The good approximation is evident. 
and the modulus of $\underline{\underline{i}}_{\underline{m}}$ is:

$\mathrm{I}_{\mathrm{m}}=\left(\mathrm{i}^{2}{ }_{\mathrm{s}}+\mathrm{i}_{\mathrm{r}}^{2}\right)^{0.5}$

- Hence, the stator and rotor voltage equations in a $d-q$ general reference frame rotating at an arbitrary speed $\omega_{a}$, are derived giving:

$$
\begin{aligned}
& V_{s d}=R_{s} i_{s d}+L_{s l} \frac{d i_{s d}}{d t}+\frac{d \Psi_{m d}}{d t}-\omega_{a}\left(L_{s l} i_{s q}+L_{m} i_{s q}+L_{m} i_{r q}\right) \\
& V_{s q}=R_{s} i_{s q}+L_{s l} \frac{d i_{s q}}{d t}+\frac{d \Psi_{m q}}{d t}+\omega_{a}\left(L_{s l} i_{s d}+L_{m} i_{s d}+L_{m} i_{r d}\right) \\
& V_{r d}=R_{r} i_{r d}+L_{r l} \frac{d i_{r d}}{d t}+\frac{d \Psi_{m d}}{d t}-\left(\omega_{a}-\omega_{r}\right)\left(L_{r l} i_{r q}+L_{m} i_{s q}+L_{m} i_{r q}\right) \\
& V_{r q}=R_{r} i_{r q}+L_{r l} \frac{d i_{r q}}{d t}+\frac{d \Psi_{m q}}{d t}+\left(\omega_{a}-\omega_{r}\right)\left(L_{r l} i_{r d}+L_{m} i_{s d}+L_{m} i_{r l}\right)
\end{aligned}
$$

In equations (5) to (8), the $d$ and q-axes flux linkage components are substituted by:

$\Psi_{m d}=L_{m} i_{m d}$, and $\Psi_{m q}=L_{m} i_{m q}$,

where $i_{m d}$ and $i_{m q}$ are the $d$ and $q$ components of the magnetizing current respectively, and in terms of stator and rotor currents are given by:

$$
\begin{aligned}
& i_{m d}=i_{s d}+i_{r d} \\
& i_{m q}=i_{s q}+i_{r q}
\end{aligned}
$$

Rearranging equations (5) to (8) yields the following model for saturated induction machine in arbitrary, rotating reference frame:

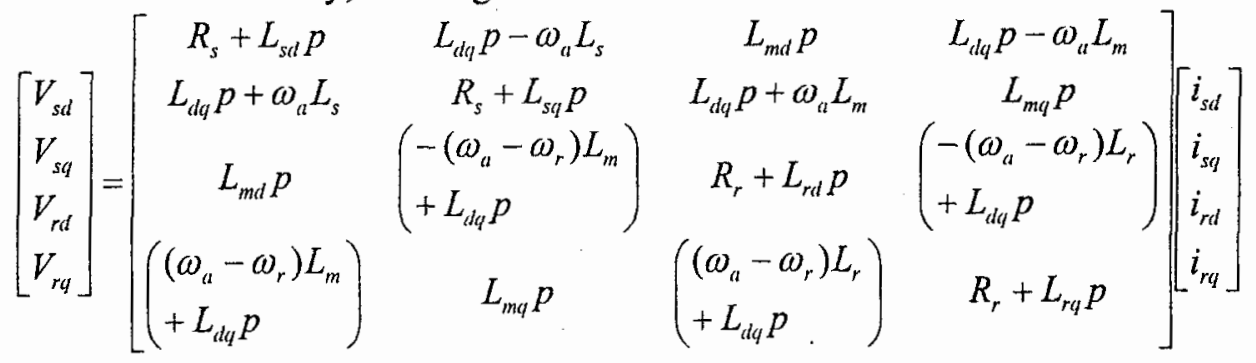

where, $\mathrm{L}_{s d}=\mathrm{L}_{s l}+\mathrm{L}_{m d}$,

$\mathrm{L}_{s q}=\mathrm{L}_{s l}+\mathrm{L}_{m q}$

$\mathrm{L}_{r d}=\mathrm{L}_{r l}+\mathrm{L}_{m d}$,

$\mathrm{L}_{r q}=\mathrm{L}_{r l}+\mathrm{L}_{m q}$

The electromagnetic torque equation is:

$$
T_{e}=1.5 N_{p} L_{m}\left(i_{s q} i_{r d}-i_{s d} i_{r q}\right)
$$

The mechanical torque equation is

$$
T_{e}=\frac{J}{N_{p}} p\left(\omega_{r}\right)+\frac{K}{N_{p}} \omega_{r}+T_{L}
$$

The voltage equation for the dc link shown in Fig.(1) is

$$
V_{r}=r_{f} i_{d c}+X_{f} p i_{d c}-V_{i}
$$


Neglecting the commutaung inauctance, the average uutput voltage vi a tull unugu

converter is: $V_{d}=\frac{3 \sqrt{3}}{\Pi} V_{p} \cos \alpha$

Where,

$\mathrm{V}_{d}=\mathrm{V}_{\text {rec }}$ for the rectifier, $\mathrm{V}_{d}=\mathrm{V}_{i}$ for the inverter, $\alpha=$ firing angle, and $\mathrm{V}_{p}$ is the peak value of ac phase voltage (rotor voltage for the rectifier and source voltage for the inverter).

\section{FUZZY LOGIC COONTROLLER (FLC)}

\subsection{Fuzzy logic approach}

Fuzzy logic (FL) offers a powerful tool to implement a controller, deals with the non-linearities of the SSPRD. The advantages of the FL controller over conventional controllers are its nonlinear control actions, less dependence on mathematical model, better noise rejection, and less sensitivity to parameters variation. Figure.(4) shows the block diagram of a fuzzy system, which includes a fuzzification block, a knowledge base, a fuzzy inference engine, and a defuzzification block. The fuzzification process maps a crisp point of real meaning(data) into fuzzy sets by the knowledge of the input membership function. The knowledge base of the fuzzy system stores the expert knowledge on how to control the machine, while the inference engine stores the information on how a human operator would use this knowledge to control the plant. The fuzzy inference engine uses the rules in the rule base to produce fuzzy sets at its output, corresponding to its input fuzzy sets. Finally, the defuzzification process uses the knowledge of the output membership function to map the output fuzzy sets into a crisp value that is usable.

\subsection{Fuzzy Logic Controller For SSPRD}

The fuzzy controller's strongest asset is its knowledge base. The knowledge base includes the choice of the input-output membership functions, and the rule base. Typically, uniformly disrtibuted triangular membership functions are used in order to simplify digital implementation. This paper uses uniformly distributed triangular membership functions, shown in Fig.(5) for both the input and output of the FL controller. The inputs of the FL controller are, the speed error (err) and the change in speed error (c-err). The FL controller output is the rotor current command used to compensate for any speed error. This command is used to adjust the inverter firing angle to track the reference speed.

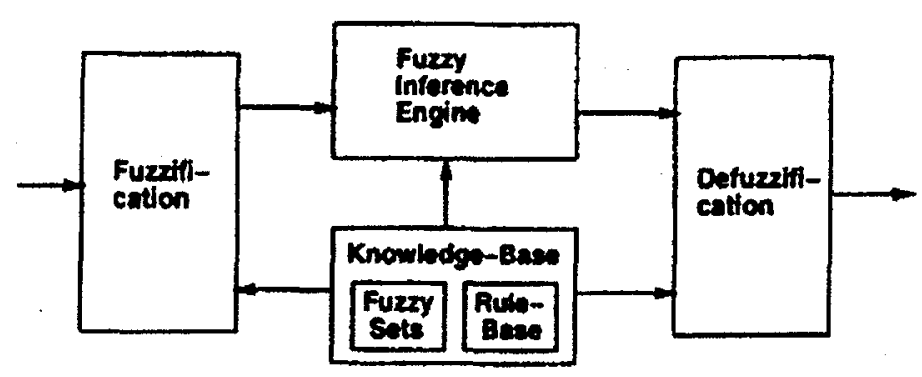

Fig.(4) Block Diagram of a Fuzzy System 
The membership functions shown in Fig.(5) are denoted by NL (negative large), NM (negative meduim), NS (negative small), ZE (zero), PS (positive small), PM (positive

* meduim), and PL (positive large). The linguistic control rules relating the inputs and output of the FL controller are shown in Table (1). This rule base is designed to have large changes in the current command when the error and/or change in error are large. When the error and change in error are zero, the fuzzy controller has reached the command speed, and is holding at the speed. If any disturbance occurs, the rules change the current to keep the speed at the reference value.

Table (1)

\begin{tabular}{|l|l|l|l|l|l|l|l|}
\hline $\begin{array}{c}\text { C-err } \\
\text { err }\end{array}$ & NL & NM & NS & ZE & PS & PM & PL \\
\hline NL & PL & PL & PL & PM & PM & PS & ZE \\
\hline NM & PL & PL & PM & PM & PS & ZE & NS \\
NS & PL & PM & PM & PS & ZE & NS & NM \\
ZE & PM & PM & PS & ZE & NS & NM & NM \\
PS & PM & PS & ZE & NS & NM & NM & NL \\
PM & PS & ZE & NS & NM & NM & NL & NL \\
PL & ZE & NS & NM & NM & NL & NL & NL \\
\hline
\end{tabular}

The foilowing example shows how these rules are executed :

For the first entry in the table, if the speed error is NL and the change in speed error is NL, then the output current command is PL.

From the rule base table, the inference engine produces a fuzzy value for change in current. A crisp numerical value of change in current is then obtained via defuzzification procedure. "Singleton" fuzzification and "center of gravity" defuzzification are employed. "Sup-Min" inference method is used for fuzzy implications.

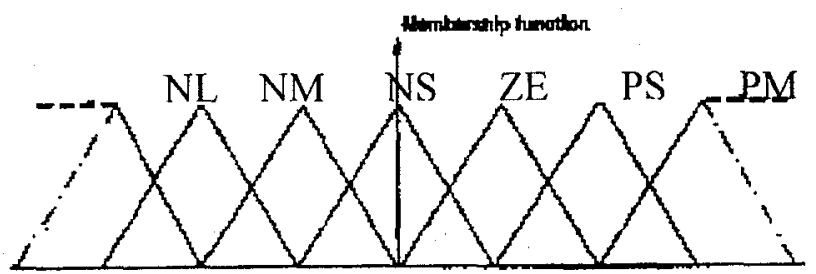

Fig.(5)Triangular Membershin Function 
Simulation is conducted for a $1.5 \mathrm{Kw}$ saturated slip ring induction machine using the dynamical model of the system as derived in section 2 , with the fuzzy logic controller described in section 3. This is followed by simulation sessions for the SSPRD incorporating the conventional PI controller. The data of simulated machine is given in the appendix.

Figure (6) shows the speed of the FL controlled SSPRD at start up, while Fig.(7) shows the same characteristic for the PI controlled SSPRD. Comparing these figures, similar starting characteristics are obtained for both the FL and the PI controlled SSPRD.

Figures (8) and (9) show the speed tracking characteristics after a step change in speed command for the FL controlled and PI controlled drives respectively. It is clear that.reasonable speed tracking of the PI controlled drive occurred, but with a small steady state error. While for the FL controlled drive, accurate speed tracking took place without steady state error, as expected.

The simulation is repeated to examine the disturbance rejection capabilities of each controller, when a load is suddenly applied. Figure (10) shows the speed response of the FL controlled SSPRD after a sudden application of $5 \mathrm{~N}$. m. load torque at $t=4.5$ secs. With the drive speed initially at $1350 \mathrm{rpm}$, the fuzzy controller returns the speed to the command speed within 1.5 seconds with a maximum speed drop of 7 rpm. Similar conditions are applied to the PI controlled drive with response shown in Fig.(11). The PI controlled SSPRD returns to the speed command also within 1.5 seconds, but with a maximum speed drop of $14 \mathrm{rpm}$,i.e. double the speed drop in the case of the FL controlled SSPRD. Another descripency occurred in the PI controlled drive, which is the steady state error of $7 \mathrm{rpm}$. This value represents about $0.5 \%$ from the original drive speed.

The effect of parameter variation is next tested by tripling the rotor resistance at $t=$ 4.5 second, while the machine is loaded. For the FL controlled SSPRD response shown in Fig.(12), the controller manages to return the speed to its reference value within 1.5 secs., with a maximum dip of $15 \mathrm{rpm}$, and without steady state error. Under the same conditions, the PI controller performs poorly, as shown in Fig.(13). The PI controller returns to the command speed, within 1.5 seconds, with a maximum dip of $20 \mathrm{rpm}$, and with a steady state error of $5 \mathrm{rpm}$. It is worth noticing that the speed dip in the case of PI controller is twice the speed dip in the case of the FL controller.

The effect of parameter variation on the controllers' performances is further tested at four times the rotor resistance value. For the FL controller response shown in Fig.(14), the controller manages to return the speed to its reference value within approximately 2 seconds., with a maximum dip of $20 \mathrm{rpm}$, and without steady state error. Under the same conditions, the PI controller performs poorly, as shown in Fig.(15). The PI controller returns to the command speed with a steady state error of $6 \mathrm{rpm}$ with a maximum dip of $40 \mathrm{rpm}$. Similar to the case of tripling the rotor resistance, the speed dip that took place with the PI controller has twice the value of the dip that took place with the FL controller. 
From the simulation results it is clear that a steady state error in the drive speed always takes place in the PI controlled SSPRD, which is not the case for the FL - controlled drive.

\section{CONCLUSION}

This paper successfully demonstrates that a properly designed fuzzy logic controller can outperform traditional PI controller when applied to saturated slip power recovery drives. This is demonstrated from a comparison between the performances of the FL controlled saturated slip power recovery drive (SSPRD), and the PI controlled SSPRD presented in this paper.

The nonlinear magnetizing reactance is derived from the induction machine no-load test Saturation effect is then accounted for using a polynomial approximation for the proper consideration of the nonlinear magnetizing reactance.. Introducing the saturation effect, the start up and dynamic responses for the FL controlled SSPRD are presented and compared with those of the PI controlled SSPRD. The dynamic responses are given, for the speed, load torque, and rotor resistance variations.

Based on simulation results, the following conclusions are obtained

(1) The fuzzy logic controller can be tuned to a single setting such that the speed tracks step commands with zero steady state error without overshoots. The PI controller tracks the speed command but with steady state error.

(2) The FL controller is more robust than the PI controller when load disturbances occurs.

(3) The FL controller performances when motor parameters are increased by a factor of three or four, were still quite good and far better than the PI controller's performnce when the same parameters are changed.

In short, fuzzy logic provides a means for synthesizing a controller from engineering experiences that can be more robust, have better performance, and insensitive to parameter variations.

\section{REFERENCES}

1.E.Akinpar and P. Pillay, "Acomputer program to predict the performance of slip energy recovery induction motor drives", IEEE Trans. on EC, Vol.5, No.2, June 1990, pp357-365.

2.E.Levi, "Impact of Cross-Saturation on Accuracy of Saturated Induction Machine Models", IEEE Trans, EC, Vol.12, No.3, Sept.97.

3.Y.Tang and L.Xu, "Fuzzy Logic application for intelligent control of a variable speed drive", IEEE Trans on EC, Vol 9,No.4,Dec.1994,pp679-685.

4.D.Hofmeyer and W. Hofmann, "Applying fuzzy control to electric drive systems", IPEC'95 conference proceedings, Japan, 1995, pp64-69.

5.A.Cataliotti, and G. Poma, "A fuzzy logic approach for easy and robust control of an induction motor", EPE'97, Trondheim,Norway,1997,pp421-425. 


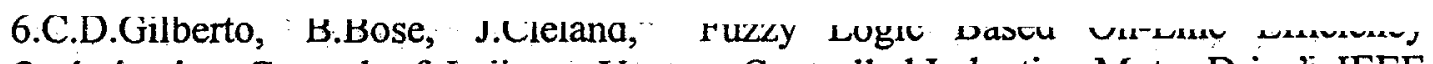
Optimization Control of Incirect Vector-Controlled Induction Motor Drive', IEEE Trans.IA, Vol.42,No.2, April 1995,pp192,198.

7. C.Liaw, J.B.Wang, and Y.C.Chang, "A Fuzzy Oriented Mechanism For Induction Motor Drive”, IEEE Trans., EC, Vol.11, No. 1, March 1996, pp76-83.

8. T.C. Huang, and M.A. El-Sharkawi, "High Performance Speed and Position Tracking of Induction Motors Using Multi-Layer Fuzzy Control", IEEE Trans. ,EC, Vol.11, June 1996, pp353-358.

\section{APPENDIX}

Machine parameters:

$1.5 \mathrm{Kw}, 50 \mathrm{~Hz}, 4$ pole slip ring induction machine, 220/380 v, 7/4amp.,

$\mathrm{R}_{\mathrm{s}}=3.56 \mathrm{ohm}, \mathrm{R}_{\mathrm{r}}=5.22 \mathrm{ohm}$, $X_{\mathrm{ls}}=\mathrm{X}_{\mathrm{lr}}=2.82 \mathrm{ohm}$.

Rated speed $=1440 \mathrm{rpm}$

$\mathrm{J}=.09 \mathrm{~kg} \cdot \mathrm{m}^{2}$

$\mathrm{K}=0.003 \mathrm{Nm} . / \mathrm{rad} . / \mathrm{sec}$ 
$*$

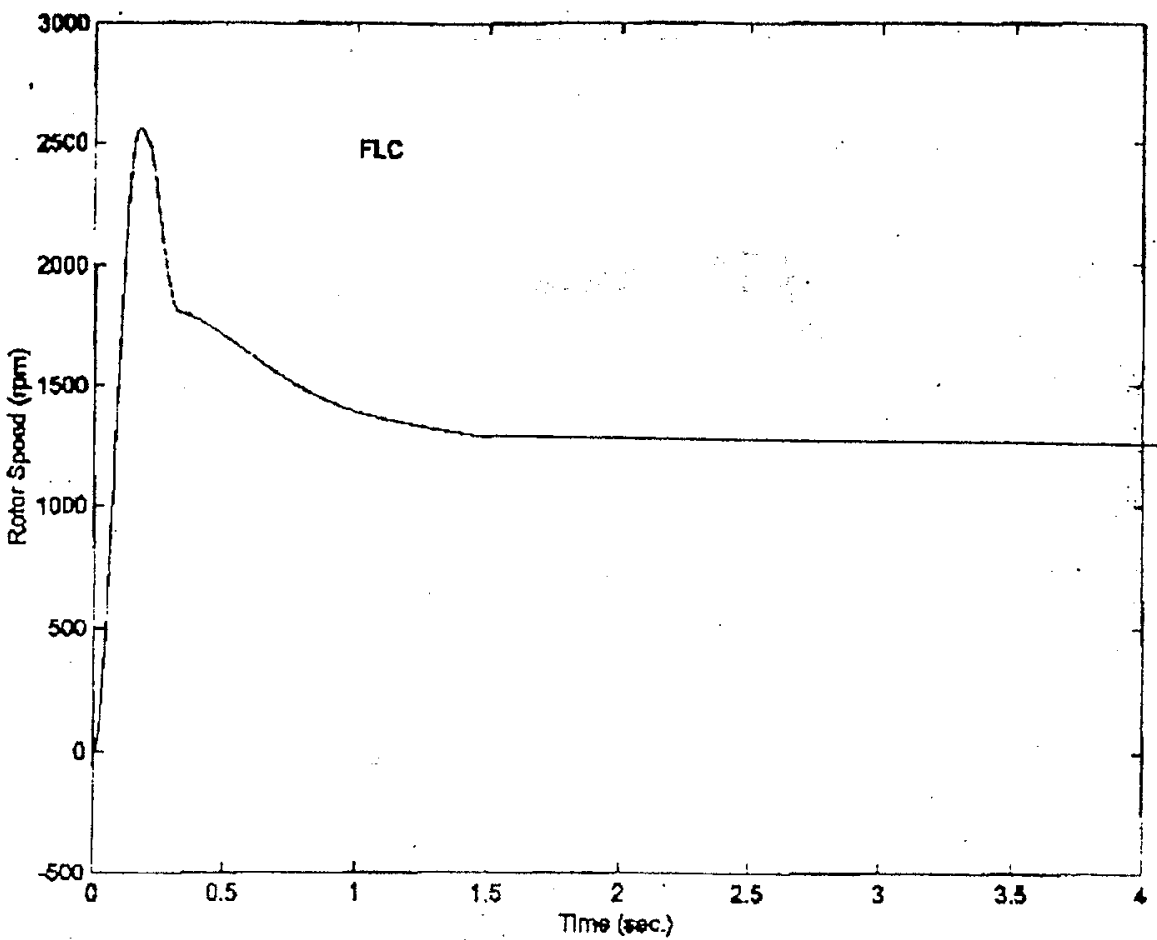

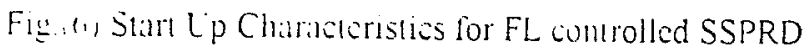

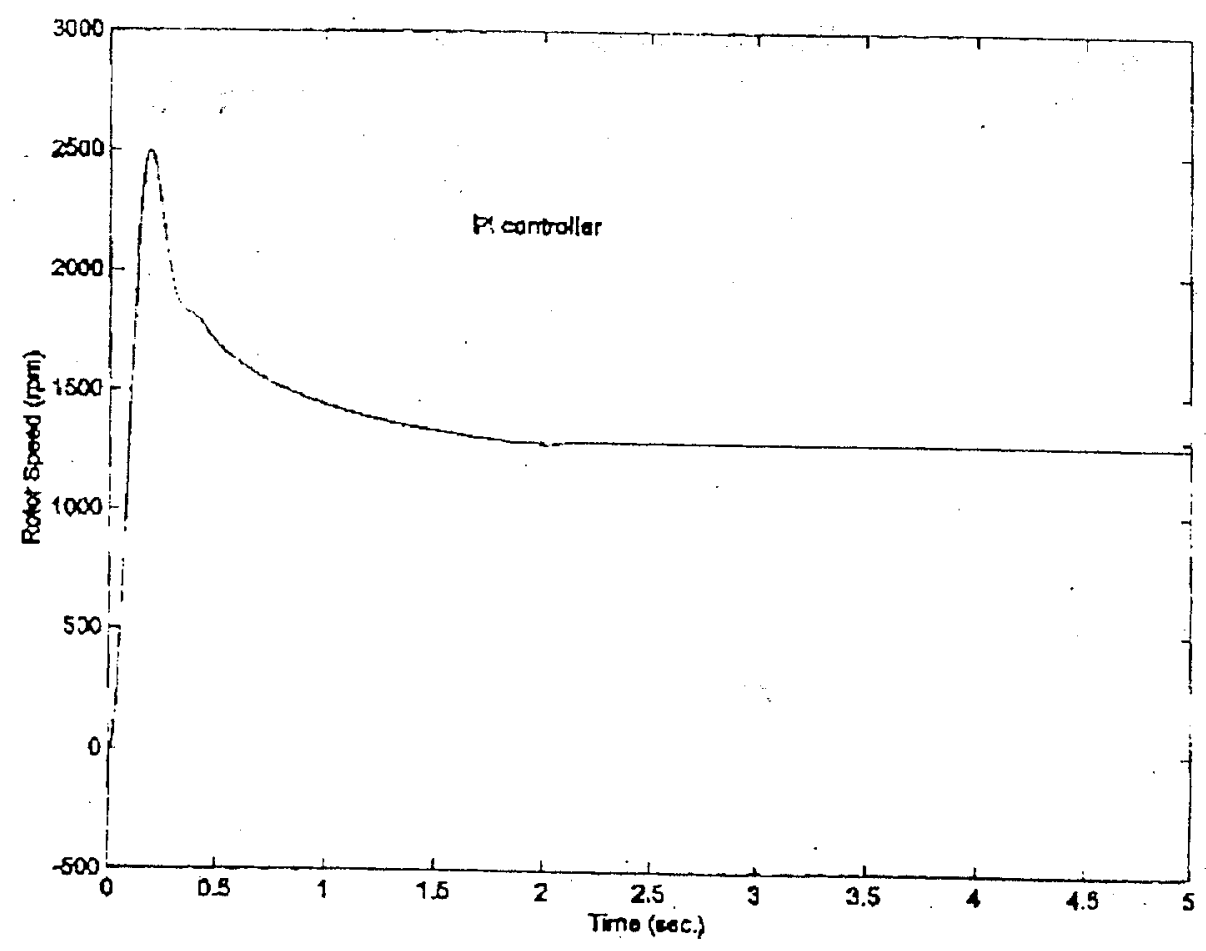

Fig. $1^{-}$) Start Lp Characteristics for PI controlled SSPRD 


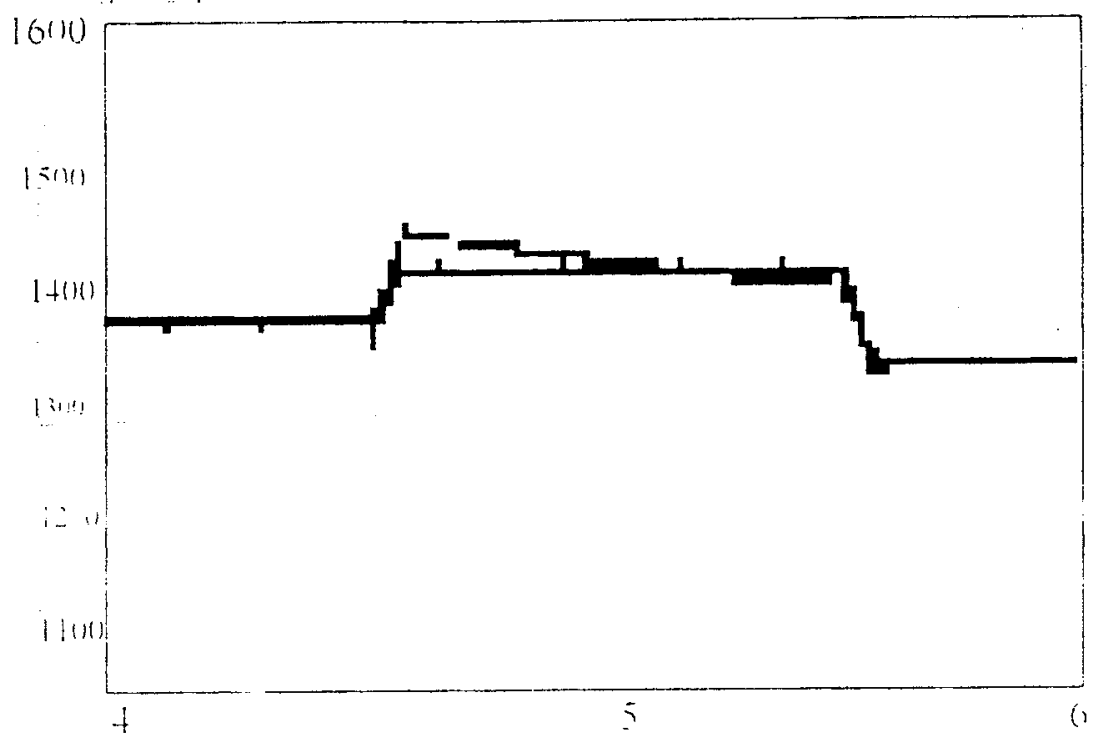

Timelsec)

Fig.(8) FL controied SSPRD speed response afiu step change in reference speed

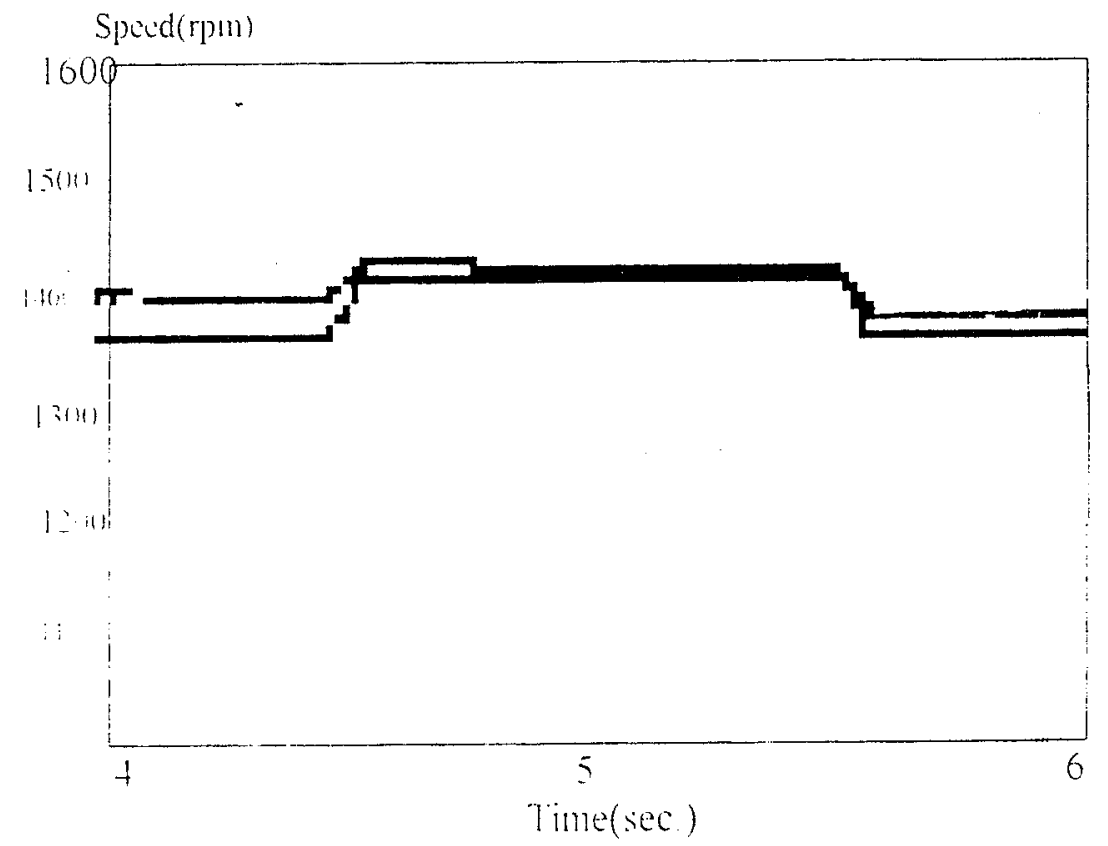

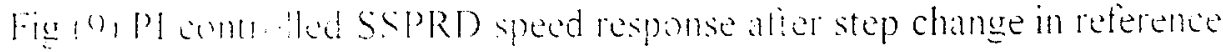
speed 
pechipun

,

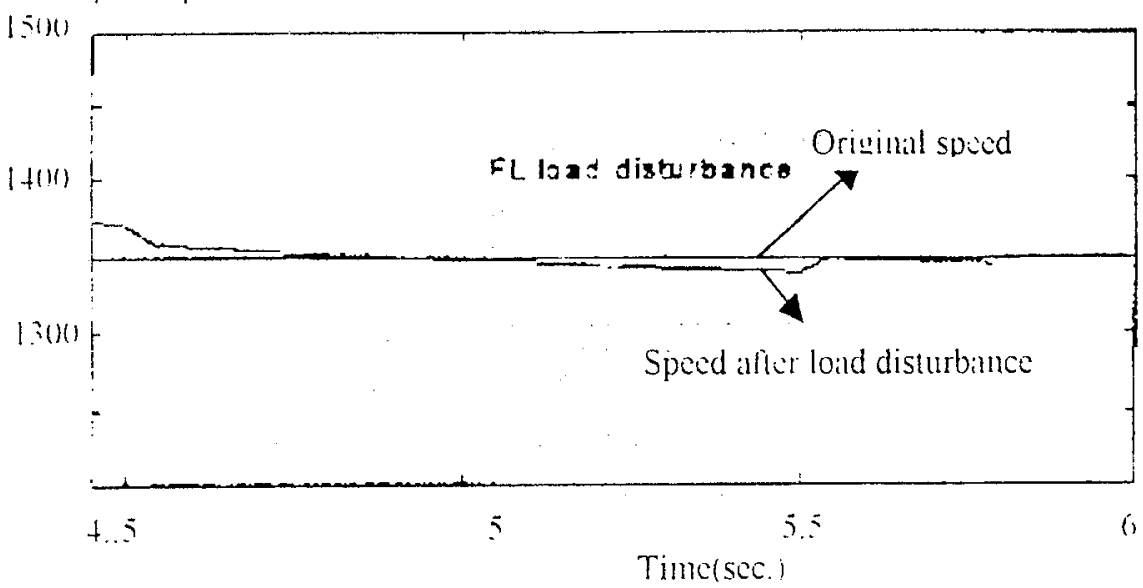

Fig. (10) FL connolled SSPRD speed response after step change in the load torque

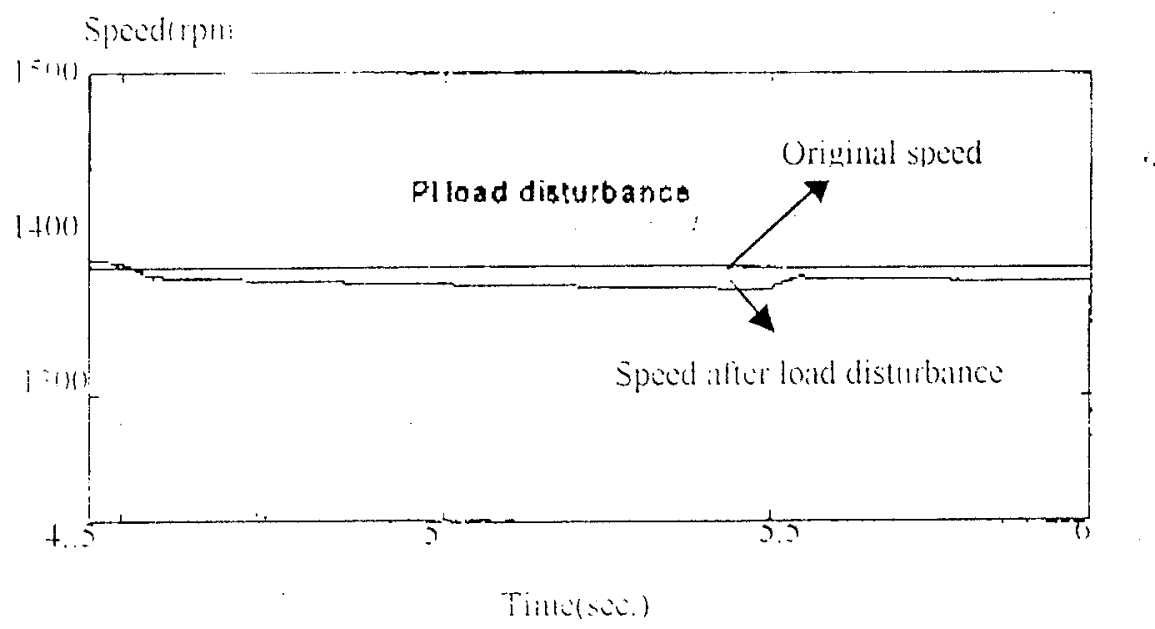

Fir (II) PI comm *!led SSPRI) speed response ater step change in the loat torgue 
speea(rрm)

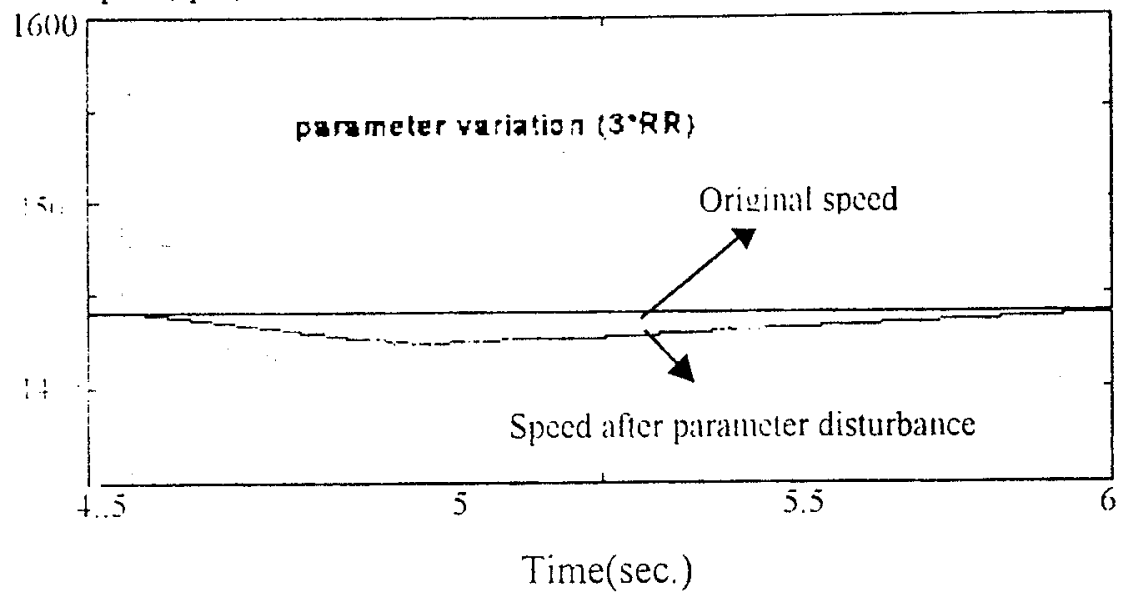

Fig (12) FL controlled SSPRD speed response at 3 times the rotor resistance

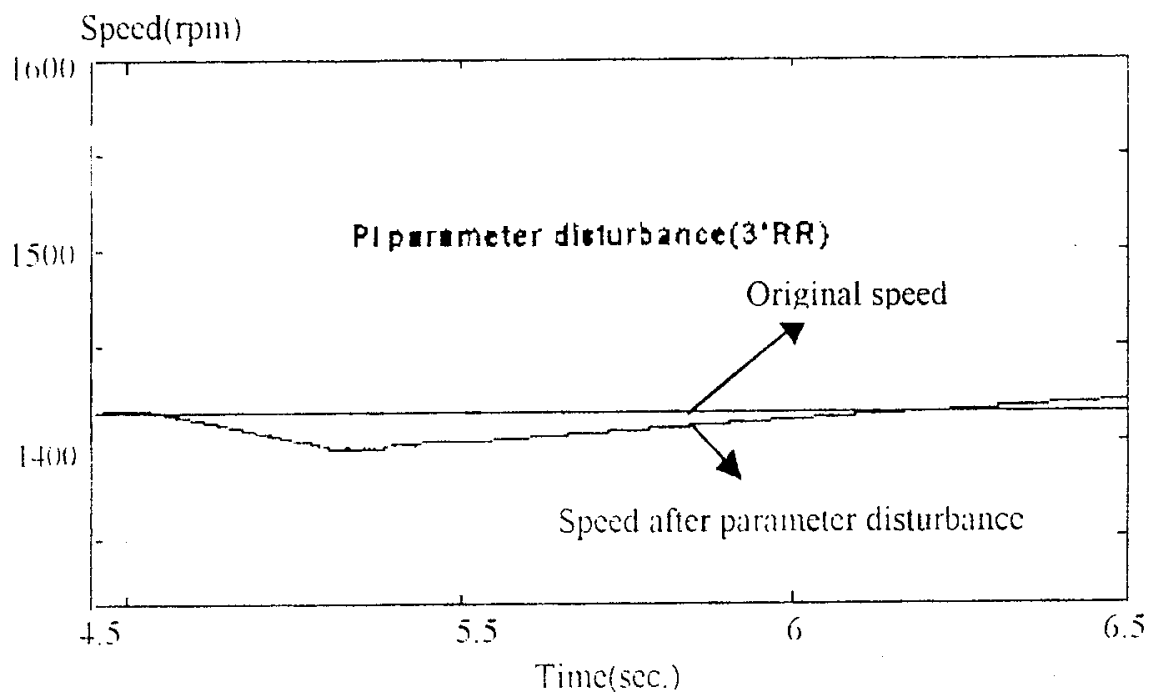

Fin. (13) PI controlled SSPRD speed response at 3 times the rotor resistance 


\title{
استخدام المنطق غير المحدد في التحكم في الماكينات الحثية المشبعة
}

\author{
منى نجيب اسكندر \\ معهد بحوث الأكترونيات
}

قسم الكترونيات الطاقة العالية و تحويل الطاقة

تم في هنا البحث دراسة طريتتان اللتحكم فى محرك حثي نو قدرة انزلاق مستعادة بعمل فى جالة التشبع و هما طريقة المنطق غير المجدد و طريقة التكامل التناسبي ز وقد تم تمثيل حالة الشبع بمعادلة تقريبية مستتجة من اختبار الماكينة الحثية فى حالة عدم التحميلز ونلاك لتمثيل المغناطيسية غير الخطية

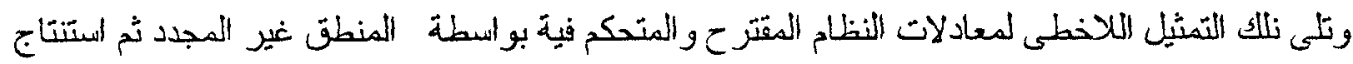
خواص النظام المقترح عند بدء التشغيل ثُ عند التغيير المفاجىء في السرعة والحمل وايضـا التغير في مقاومة

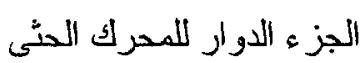
ثم تمت دراسة خو اص النظلم المتحكم فية بطريقة التكامل التتاسبي عند بدء المشغيل ثم عند التخيير المفاجىء في "البر بعة والحمل وايضا التغير في مقاومة الجز ء الدوار للمحرك الحثى ومقار نتة بالنظلم النسابق وقد اثبتت لب، ئلاك المقارنة ان المحرك الحثي نو قدرة الانز لاق المنتعادة والنى يعمل فى جالة التشبع المقتر ح و المتحكم فية بواسط. المنطق غير المجدد نو الستجابة سريعة للتغير ات في السر عة والاحمال ونو دقة عالية وحساسية منخفضة للتغيز في مقاومة الجزء الدوار للمحرك الحثى مما يوكد كونة نظاما امنل للتحكم 


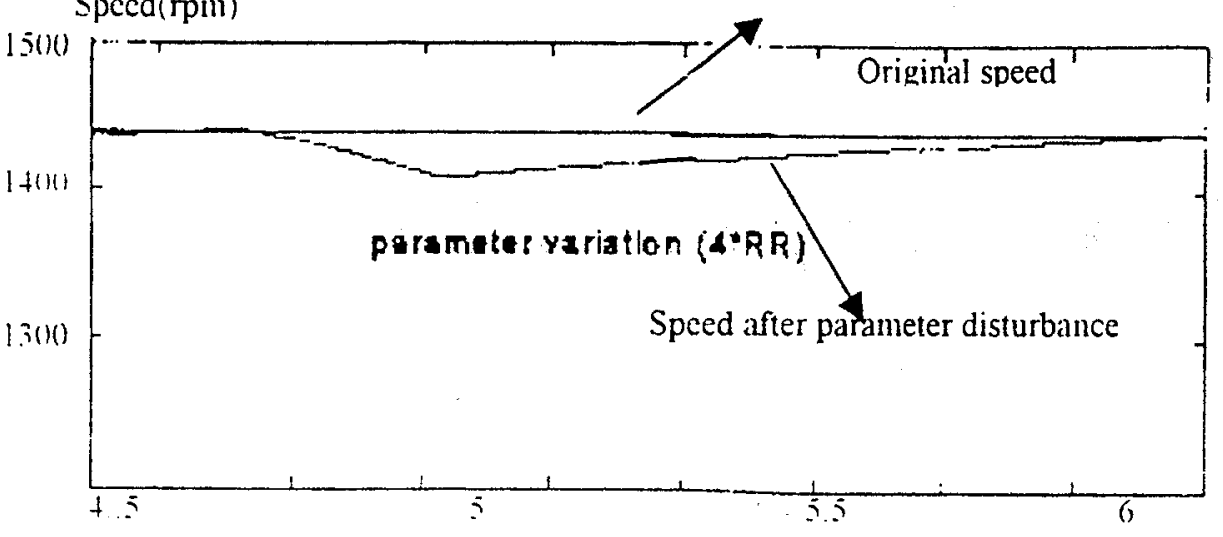

Time(sec.)

Fig (14) FL controlled SSPRD speed response at 4 times the rotor resistance

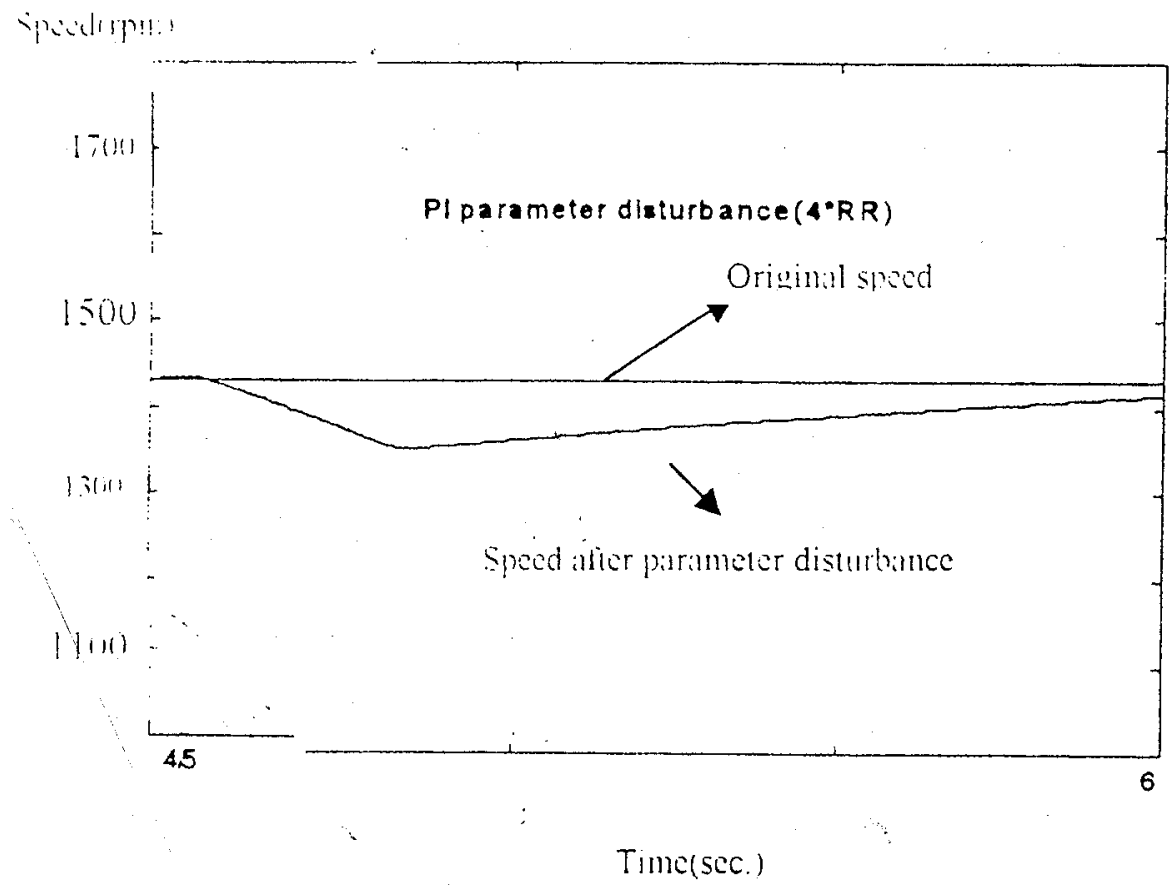

Fig.115) Pl contrilled SSPRD speed response at 4 times the rotor resistance 